\section{La comunalidad como práctica de autonomía indígena: aproximaciones desde una experiencia mixe (Oaxaca, México)}

\author{
MARÍA IGNACIA IBARRA ELIESSETCH ${ }^{1}$ \\ 0000-0002-4876-3184 \\ Universitat de Barcelona, España \\ Centro de Estudios Interculturales e \\ Indígenas (CIIR), Chile
}

\section{DANIELA CARRASCO ORELLANA ${ }^{2}$ 0000-0002-5078-665X \\ El Colegio de Michoacán, México}

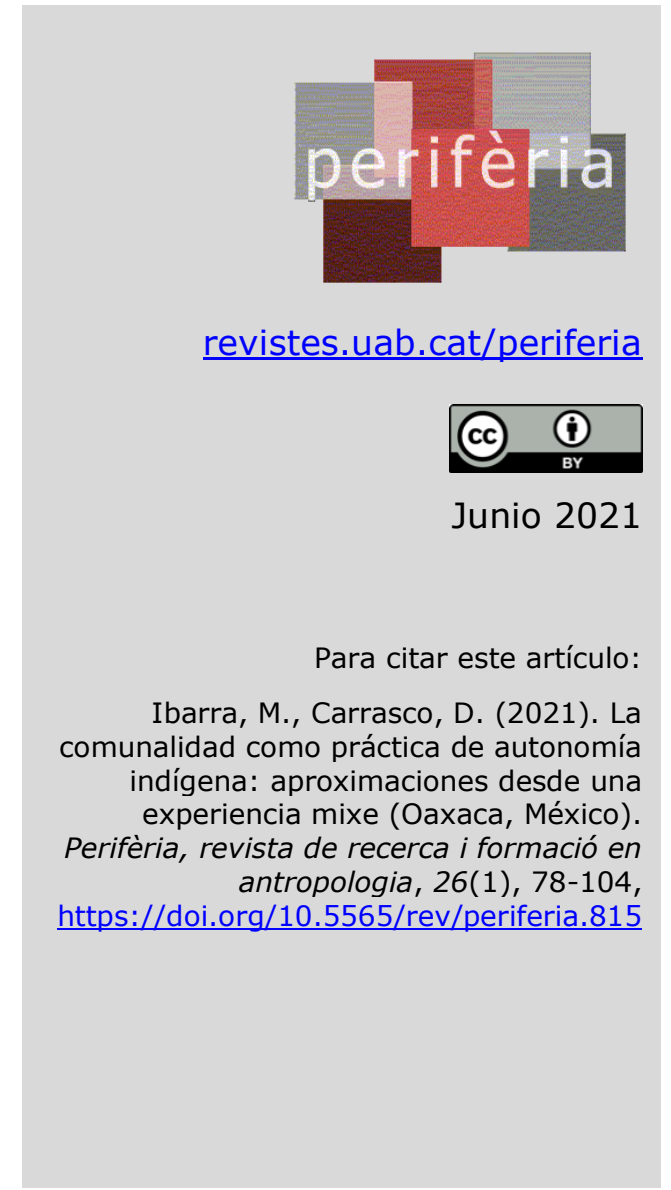

\title{
Resumen
}

La autonomía territorial es una de las principales demandas de los pueblos indígenas en Latinoamérica en tiempos contemporáneos. Este artículo es el resultado de una experiencia etnográfica que tuvo como objetivo explorar las configuraciones sociopolíticas de la comunidad mixe de San Pedro y San Pablo Ayutla (Oaxaca, México) donde se observó la administración local de un sistema normativo interno, también llamado de "usos y costumbres". Aproximarse a las formas de convivencia y en los entramados comunitarios de este pueblo permitió reconocer la relevancia de una organización política local para mantener y potenciar la comunalidad y autonomía de este territorio.

Palabras clave: Comunalidad; Sistema normativo interno; Usos y Costumbres; Autonomía; Territorio.

\footnotetext{
${ }^{1}$ Contacto: María Ignacia Ibarra Eliessetch - ignacia.ibarra@gmail.con

${ }^{2}$ Contacto: Daniela Carrasco Orellana - d.carrasco01@gmail.com
} 
Abstract: Commonality as a practice of indigenous autonomy: approaches from a mixe experience (Oaxaca, Mexico).

Territorial autonomy is one of the main demands of indigenous peoples in Latin America in contemporary times. This article is the result of an ethnographic experience that aimed to explore the socio-political configurations of the Mixe community of San Pedro and San Pablo Ayutla (Mexico) and observe the local administration of an internal normative system, also called "uses and customs". Approaching the forms of coexistence and the community frameworks of this town allowed us to recognize the relevance of a local political organization to maintain and enhance the communality and autonomy of this territory.

Keywords: Commonality; Internal normative system; Autonomy; Customs and habits; Territory.

\section{Contexto de San Pedro y San Pablo Ayutla: una comunidad mixe en la sierra norte de Oaxaca}

Este artículo retoma parte de las reflexiones y hallazgos de la investigación plasmada en la tesis Participación política y comunitaria de mujeres de una comunidad mixe: Etnografía en San Pedro y San Pablo Ayutla (2015). La investigación se desarrolló a partir de la etnografía realizada en las verdes montañas mixes durante 4 meses, en medio de la espesa neblina que caracteriza a aquella franja de la sierra. Los mixes son un pueblo indígena que se ubica en el noreste del Estado de Oaxaca. El autónimo mixe es Ayuujkjä'äy, el cual proviene de la lengua ayuujk y significa "pueblo de la lengua florida". San Pedro y San Pablo Ayutla es la comunidad de entrada a la sierra viniendo desde la ciudad de Oaxaca. El trabajo de campo fue realizado el año 2014 durante los meses de junio y diciembre. La recolección de datos involucró la realización de observación participante, recorridos comentados (Evans y Jones 2011), entrevistas semiestructuradas y en profundidad. Las colaboradoras del estudio fueron mujeres y hombres de 18 años de edad en adelante, residentes en la cabecera municipal de la comunidad de Ayutla. El análisis de datos fue principalmente descriptivo-interpretativo con base a una revisión exhaustiva de bibliografía en torno al estado del arte. 


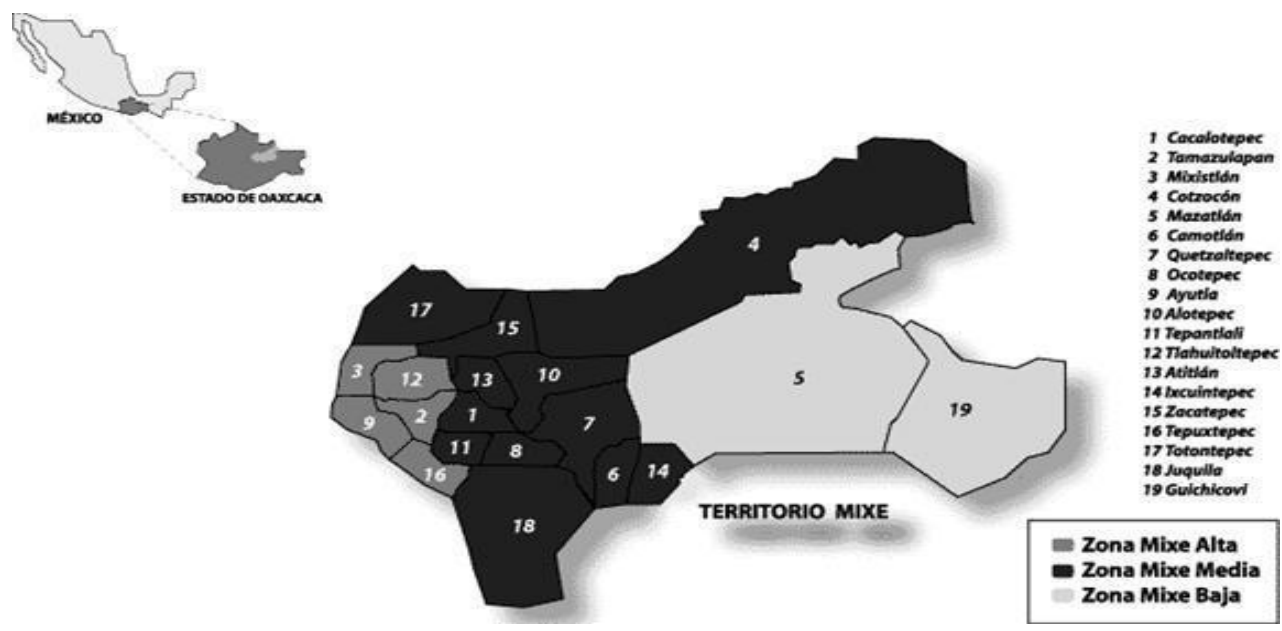

Mapa 1: Sierra mixe (norte de Oaxaca) dividida por zonas. Fuente: López y Barajas, 2013, p. 12.

La comunalidad es la configuración sociopolítica que nos permite reconocer los grados de autonomía que tiene el pueblo mixe en relación con el territorio. La autonomía territorial es una de las principales demandas de los pueblos originarios en Latinoamérica (Marimán, 2012; Ulloa, 2010). La experiencia Mixe nos permite comprender la potencia de la autonomía comunitaria a través de la organización de la comunidad.

Es fundamental reconocer que los procesos autonómicos son tan variados como los pueblos mismos que han emprendido este camino. La autonomía, "entendida como forma de manifestación interna de la autodeterminación, se puede dar a su vez en distintos grados, esto es, con mayor o menor amplitud de autogobierno, así como en el marco de diferentes estrategias" (Aparicio, 2009, pp. 15-16). En ese sentido, el horizonte autonómico puede ser tan variopinto que puede abarcar desde la búsqueda de independencia y/o la construcción de un Estado nacional (como el caso mapuche en Chile), hasta la conformación de autonomías dentro de los marcos normativos de la sociedad nacional (Sánchez, 2010, p. 260). Al mismo tiempo, la autonomía se puede apropiar desde distintos elementos, enfocándose en cuestiones específicas de autogobierno, participación, jurisdicción indígena, administración presupuestal, entre otros; mientras en otros casos -como los zapatistas (Chiapas) - se relaciona al "control territorial, el gobierno propio, la jurisdicción indígena, el manejo ambiental y soberanía alimentaria, entre otros temas" (Ulloa, 2010, p. 77), que implican todos los frentes de la vida de la comunidad. 
Es por ello que este artículo pretende aportar a estas comprensiones de autonomía por medio de la experiencia etnográfica sobre (i) el sistema normativo interno de cargos de usos y costumbres como un eje de la vida política que permite la expresión y participación de la colectividad en la comunidad; (ii) la construcción de la participación comunitaria como un proceso contencioso que ha implicado transformaciones, ambivalencias 0 , incluso, disidencias sobre el sistema normativo interno y la comunalidad; y, (iii) la autonomía relacional indígena a través de la toma de decisiones sobre los modos de vida comunales que inciden en el territorio y la territorialidad.

\section{Comunalidad, tierra y territorio: elementos claves en su sistema político}

La tierra y el territorio, que les dan pertenencia e identidad, son sagrados para el pueblo mixe. La tierra es la madre, fuente de la vida y no existe una separación entre ella y los seres humanos, percibidos como sus hijos e hijas. Pero la tierra también es territorio, y en la cosmovisión ayuujk, como en la de otros pueblos originarios, cada elemento natural tiene su función dentro del todo; está presente el concepto de integralidad (Hoechli, 2013, p. 26).

El significado simbólico de la tierra en tanto territorio tiene que ver con un pasado histórico que los mixes defienden como parte de su identidad. El territorio es el sustrato material y simbólico que cobija la vida comunitaria y que permite el crecimiento de la comunidad. Su centralidad se despliega tanto en la vida cotidiana como en la ritual (compuesta de tradiciones, ritos o ceremonias), ambas ancladas en una fuerte religiosidad basada principalmente en la sacralización de la tierra y de lugares simbólicos (como las montañas). 


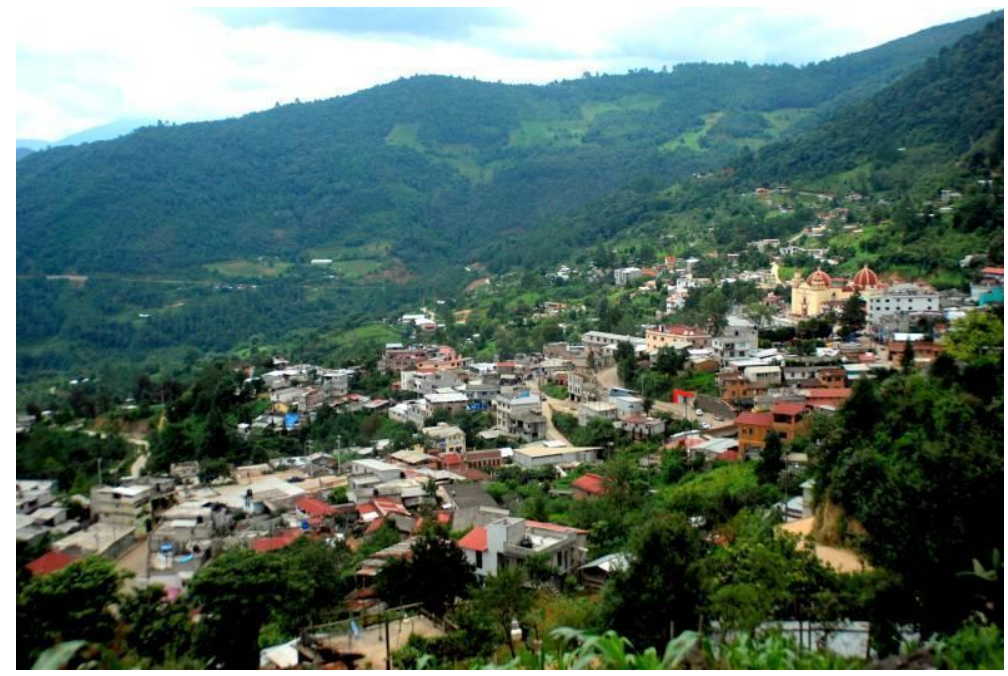

Imagen 1: San Pedro y San Pablo Ayutla. Fuente: Ibarra, 2015, p. 7.

De acuerdo a Elden (2010) el concepto de territorio se puede desagregar en tres dimensiones interrelacionadas: tierra (land), que se vincula al ámbito políticoeconómico; terreno (terrain) que da cuenta de lo político-estratégico; y, territorio (territory), que refiere a las matrices político, económicas y sociales que posibilitan el control sobre la tierra y el terreno (Elden, 2010). Sin embargo, debemos comprender que cuando las comunidades indígenas hablan de tierra refieren, generalmente, al territorio, el cual es también un espacio apropiado simbólica y materialmente por las comunidades (Barabas, 2014).

El apego al lugar y al territorio (Altman \& Low, 1992; Nogué, 2015) se relaciona con el sentido de comunalidad que caracteriza a las comunidades mixes, la cual se basa, principalmente, en ciertos elementos que los constituyen como parte de una cultura. Así describió Floriberto Díaz, antropólogo mixe oriundo de la comunidad vecina de Tlahuitoltepec, el concepto de comunalidad:

[...] para mí la comunalidad define la inmanencia de la comunidad. Dicho lo anterior podemos entender los elementos que la definen: la Tierra como madre y como territorio; el consenso en asamblea para la toma de decisiones; el servicio gratuito como ejercicio de autoridad; el trabajo colectivo como un acto de recreación; los ritos y ceremonias como expresión del don comunal (Díaz Gómez, 2004, p. 367). 
Vemos que el concepto de comunalidad es clave para comprender los modos de habitar el territorio ${ }^{3}$ y de organizarse, lo que nos muestra las diferencias que existen entre una comunidad indígena mixe como la de Ayutla y una urbana occidental. Es importante destacar que en el pueblo mixe ( $y$ en las comunidades indígenas en general) existen formas de relacionarse, de ser y estar en el mundo que son propias de una cosmovisión que interpreta su existencia humana en unión con la naturaleza (Ulloa, 2015). Así, el entorno se establece en convivencia social y política a través de la vida comunitaria y familiar: el sentido de lo colectivo es fundamental (en detrimento de lo individual), lo cual se traduce en su manera de poseer la tierra, que se procura que sean comunales y no privadas; ${ }^{4} \mathrm{y}$, donde la relación con la naturaleza es directa y permanente, siendo centrales los valores de la complementariedad y la reciprocidad entre comuneros.

\section{Configuración del sistema normativo interno $o$ de "usos $y$ costumbres"}

Un aspecto fundamental de la comunidad de San Pedro y San Pablo Ayutla es que ha mantenido una organización político-comunitaria de autogobierno basada en el nombramiento de autoridades municipales y auxiliares a través de sistema normativo interno, también llamado de "usos y costumbres". ${ }^{5}$ Además, algo que diferencia a esta comunidad de otras en la región (o México) es que las mujeres participan con los mismos derechos que los hombres. ${ }^{6}$ Incluso, la investigación (que sustenta este

\footnotetext{
${ }^{3}$ Relacionado a la orientación subjetiva de vivir en un lugar en particular (Agnew en Oslender, 1999).

${ }^{4}$ Uno de los regímenes de propiedad de la tierra en México es la comunidad agraria, donde el usufructo de la tierra es colectivo. Si bien, cada comunero (con sus familias) pueden poseer una fracción de ésta para trabajarla, la titulación de las tierras es comunal.

${ }^{5}$ Aquino prefiere usar el concepto de derecho indígena por sobre "usos y costumbres", ya que éste último implicaría una condición de subordinación ante el derecho de Estado al ser considerado un como normas ancladas en la costumbre y oralidad, más que como un sistema de derecho coherente y autocontenido (Aquino Centeno, 2013). Sin embargo, esta posición "suele acompañarse de una idealización de la tradición como fuente de derecho, y producir una visión atemporal del derecho indígena; se le llega a identificar como una sobrevivencia del pasado y no como el producto de un proceso histórico" (Sierra Camacho, 1993, p. 18).

${ }^{6}$ Es común que la participación en las comunidades agrarias y ejidos de México sea predominantemente masculina, debido a que las leyes agrarias promovidas en el México Revolucionario reconocían como comuneros a los hombres mayores de 16 años, salvo casos excepcionales, donde se podía reconocer como comunera a una viuda. En las últimas décadas las mujeres indígenas han puesto en la palestra la violencia de género, la falta de participación o la marginación que se vive dentro de las propias comunidades. Para
} 
artículo) se gestó por el crecimiento exponencial de la participación de mujeres en la vida política de la comunidad (Ibarra, 2015). En Ayutla, la organización se lleva a cabo a través de una asamblea general de comuneros donde, en teoría, los partidos políticos no tienen injerencia. ${ }^{7}$ Una regla clave es que todo ciudadano debe asumir un cargo en el Ayuntamiento, cumpliendo siempre con el escalafón de servicios determinado por la asamblea general. El nombramiento del sistema de $\operatorname{cargos}^{8}$ establece los roles que los y las comuneros/as designadas/os deben asumir obligatoriamente y de manera gratuita, disponiendo del servicio como una responsabilidad colectiva esencial para el funcionamiento de la comunidad. Este sistema aúna cargos de índole civil, religiosa y agraria. En palabras de Floriberto Gómez, el sistema de cargo de los mixes tiene entre sus características que:

Los responsables llevan un bastón, símbolo del mandato que les ha dado la comunidad. Los cargos se turnan entre los miembros adultos, siempre hombres, en forma rotativa. Generalmente duran un año, aunque en algunos casos pueden ser hasta tres. Después, la persona regresa a sus actividades normales y no tiene que responsabilizarse de otro por un tiempo relativamente largo. Los cargos no son remunerados y pueden absorber entre la mitad y la totalidad de las horas laborales. Los cargos implican gastos personales en la mayoría de los casos. Los miembros de la comunidad que sirven de mayordomos deben patrocinar parte de las fiestas religiosas y pagar otros gastos de la comunidad, además de apartarse de sus actividades económicas y agrícolas durante el tiempo que tome su mandato. Asimismo, reciben compensación en forma de prestigio dentro de la comunidad. Para sociedades occidentales individualistas que explícitamente relacionan riqueza con prestigio, esta compensación puede parecer meramente simbólica; sin embargo, dentro de las comunidades indígenas el prestigio y el respeto tienen un valor real y reconocido (Gómez Peralta, 2005, pp. 131-132).

más al respecto revisar "Los espacios conquistados: participación política y liderazgo de las mujeres indígenas de México" (Bonfil Sánchez et al., 2008).

7 Sin embargo, ha ocurrido que presidentes municipales luego se han convertido en diputados, o que se intenta permear al sistema a partir del poder político que ha brindado el ocupar un cargo en un partido.

8 Para López Bárcenas el sistema de cargos o las formas de resolución de conflictos son normas consuetudinarias que conforman el Derecho Indígena (López Bárcenas, 2002). 
Esta forma de organización sociopolítica es tradicional, mas no original del pueblo mixe ni de algún pueblo indígena. Proviene de una tradición traída desde España (y antes de los árabes del norte de África), que luego se inculcó en el territorio mexicano durante el periodo colonial, ${ }^{9}$ manteniendo ciertas tradiciones comunitarias prehispánicas que se adaptaron al nuevo orden político, económico y social que se instaló en aquel entonces. En ese sentido, es necesario comprender el derecho indígena no como "sobrevivencias del pasado", sino que éste se inserta "en las dinámicas de la historia y del poder; pero expresan también las actualizaciones que han hecho los pueblos de sus formas de ver el mundo, de situarse ante él y de articular sus proyectos de futuro" (Sierra Camacho \& López, 2013). Solo así reconocemos que existe el pluralismo jurídico, donde tanto el derecho indígena y el derecho positivo se influencian, pugnan, encuentran y, también, difieren. ${ }^{10} \mathrm{Al}$ mismo tiempo, esto nos lleva a reconocer que los pueblos indígenas han hecho un uso y apropiación estratégica de los repertorios legales del derecho positivo para defender sus formas de vida y su territorio.

Oaxaca (donde se localiza esta investigación) es el estado con más población indígena de México y con mayor población hablante de sus lenguas originarias. ${ }^{11}$ Además, se ha caracterizado en diversos momentos de su historia por la resistencia de sus pueblos a la pérdida de su cultura, de su lengua y de sus territorios. Esto ha generado una necesidad de avanzar jurídicamente y trabajar férreamente en materia de derechos indígenas. En 1995, luego de largos procesos de luchas, diálogos y

\footnotetext{
9 Sierra Camacho (1997) señala que el actual derecho indígena debe ser entendido a partir de las relaciones históricas y del sincretismo. Lo mismo comparte Durand Ponte al explicar que el sistema de cargos es "el resultado de una mezcla de formas prehispánicas de organización política, que sobrevivieron a la conquista, y el ayuntamiento español impuesto a los indígenas durante la Colonia. De tal arreglo nació un nuevo patrón de organización que incluye una ordenación jerárquica de las posiciones de autoridad" (Durand Ponte, 2007, pp. 39-40). En ese sentido, instituciones como el cabildo indígena o las cofradías fueron instituciones coloniales que se han imbricado en las prácticas locales, apropiado y transformado en el tiempo por los distintos pueblos indígenas en el territorio mexicano (Sierra Camacho, 1997, p. 135).

10 Cruz Rueda utiliza el concepto de diáspora jurídica para explicar que no solo el derecho positivo ha influido al derecho indígena, sino que el proceso también se ha dado en un proceso de doble vía y "no solo desde el Derecho positivo hacia el Derecho indígena, mostrando que este obliga a aquel "a moverse", detonando las diásporas al interior del Derecho mexicano" (Cruz Rueda, 2019, p. 132).

11 De acuerdo al Instituto Nacional de Geografía y Estadística (INEGI), en Oaxaca viven cerca de 1,165,186 personas hablantes de alguna lengua indígena (con base a datos del censo del 2010), lo que representa el 32\% nacional. Además, Oaxaca alberga 18 grupos étnicos, como zapotecos, mixes, mixtecos, triquis, mazatecos, chinantecos, mazatecos, entre otros (INEGI, 2020).
} 
consensos, finalmente se reconoció el sistema de cargos de usos y costumbres $^{12}$ como forma legítima de ejercer política en los municipios oaxaqueños. Tres años después, en 1998, se promulgó la Ley de Derechos de los Pueblos y comunidades indígenas de Oaxaca. ${ }^{13}$

En la actualidad, el reconocimiento de los "usos y costumbres" debe ser considerado en el escenario fundamental de la demanda creciente del movimiento indígena para promover este reconocimiento jurídico dentro de las formas de elección de autoridades municipales, bajo el régimen de "usos y costumbres". Especialmente, es necesario comprender su creciente importancia a raíz del reconocimiento internacional de derechos de los pueblos indígenas y de la rebelión zapatista de 1994, en Chiapas. (Canedo Vásquez, 2008, p. 407)

El levantamiento zapatista fue un punto de inflexión para visibilizar a los pueblos indígenas (de México y Latinoamérica) sobre todo en términos de reconocimiento de derechos de los pueblos indígenas (Bengoa 2007). De esta insurrección se gestaron los Acuerdos de San Andrés ${ }^{14}$ para modificar la Constitución Mexicana en materias indígenas, incluyendo demandas de autonomía elaboradas por la Comisión para la Concordia y Pacificación (COCOPA). ${ }^{15}$ Sin embargo, el gobierno federal se retractó de firmar los acuerdos, generando una contrapropuesta que se promulgó, en 2001, como la Ley Federal sobre Derechos y Cultura Indígena; un acercamiento tibio e insuficiente respecto a los acuerdos de San Andrés. Esto pone nuevamente de manifiesto la relevancia de un sistema independiente para mantener y potenciar la vida política comunitaria, principalmente porque ello permite la libre determinación y la autonomía local y municipal. Es por eso que las comunidades perpetúan esta

\footnotetext{
12 Reconocimiento realizado a través de una reforma al Código Electoral oaxaqueño (Gaussens, 2019).

13 Oaxaca ha sido uno de los estados pioneros en materia de reconocimiento de derechos indígenas (Canedo Vásquez, 2008). Además, para el 2018 se contabilizaban 417, de los 570 municipios de Oaxaca, regidos mediante el sistema de usos y costumbres (Instituto Estatal Electoral y de Participación Ciudadana de Oaxaca, 2018).

${ }^{14}$ Los acuerdos de San Andrés Larráinzar se firmaron en 1996 entre el EZLN y el gobierno Federal.

15 La COCOPA, integrada por senadores y diputados, generó una propuesta (retomando las demandas del EZLN) en puntos como 1) Reconocer a los pueblos indígenas en la Constitución general; 2) Ampliar participación y representaciones políticas; 3) Garantizar acceso pleno a la justicia; 4) Promover las manifestaciones culturales; 5) Asegurar educación y capacitación; 6) Garantizar la satisfacción de necesidades básicas; 7) Impulsar la producción y empleo y 8) Proteger a los indígenas migrantes (Sámano et al., 2001, p. 108). Estos acuerdos fueron aceptados por el EZLN, pero no por el gobierno Federal, el cual generó una contrapropuesta (que contradecían los acuerdos y el convenio 169 de la OIT).
} 
estructura organizacional, como una forma de gobernarse en términos propios. Así también lo planteó un habitante de la comunidad:

Fue la primera vez, en 1992, que se dijo así: la nación mexicana tiene una composición pluricultural sustentada originalmente en sus pueblos indígenas: la ley protegerá y promoverá el desarrollo de sus lenguas, culturas, usos, costumbres, recursos y formas específicas de organización social. Aquí ya se reconoce esta libre determinación de los pueblos. ¿Cómo? Diciendo que se protegerá y promoverá sus formas específicas de organización social. (Carlos) (Ibarra, 2015, p. 58)

Es a través de esta forma de organización política que se nombra a las autoridades locales, de las cuales se espera defiendan el territorio ( $y$ sus bienes comunales) ${ }^{16} y$ el sentido de comunalidad. El espacio político-cultural donde se eligen a las autoridades que guiarán a la comunidad es la asamblea, cuya centralidad es indiscutible:

Las asambleas comunitarias [...] siguen siendo el lugar en que se dirimen los problemas, donde se reúnen los hijos del pueblo para tomar las decisiones más importantes mediante la búsqueda del consenso, y es ahí donde se discute la elección de las nuevas autoridades. (Hernández-Díaz, 2007, p. 43)

En la asamblea, como instancia político-social, es donde se vive el sentido comunal $y$, aunque es un espacio político de álgidos debates, allí se establecen las condiciones para que todos y todas tengan la posibilidad de participar, opinar, discutir, establecer necesidades, demandar, reclamar y decidir en torno a medidas que afecten a la totalidad de la comunidad. Por ello, existen diferentes asambleas de acuerdo al asunto específico a tratar, como asambleas de elección de autoridades, de temas específicos (territoriales, de tequios ${ }^{17}$ o aguas), o de informes de los cabildos. Carlos,

\footnotetext{
${ }^{16}$ Los bienes comunales que usufructúan las comunidades son centrales tanto para la cohesión e identidad, como para el conflicto (intra e inter comunitario).

17 El tequio es un trabajo no remunerado que se presta como servicio a la comunidad. En muchas comunidades es obligatorio (por ser comunero/a) lo que implica participar en estas faenas para beneficio de la comunidad, como puede ser demarcación de linderos (por medio de zanjas y brechas), mantenimiento de infraestructura de la comunidad (edificios, caminos, canchas), actividades agrícolas (cosechas, cortafuegos, apagar incendios, etc.).
} 
comunero de Ayutla y activo participante de las asambleas comunitarias, me planteó con respecto a aquella instancia comunitaria:

Las decisiones se toman en común, aquí nadie decide individualmente. Por eso existen las asambleas comunitarias. Por eso aquí no se puede poner las cosas por escrito en un papel ino! Hay que ir a la asamblea y que todos opinen y decidan. (Carlos) (Ibarra, 2015, p. 59)

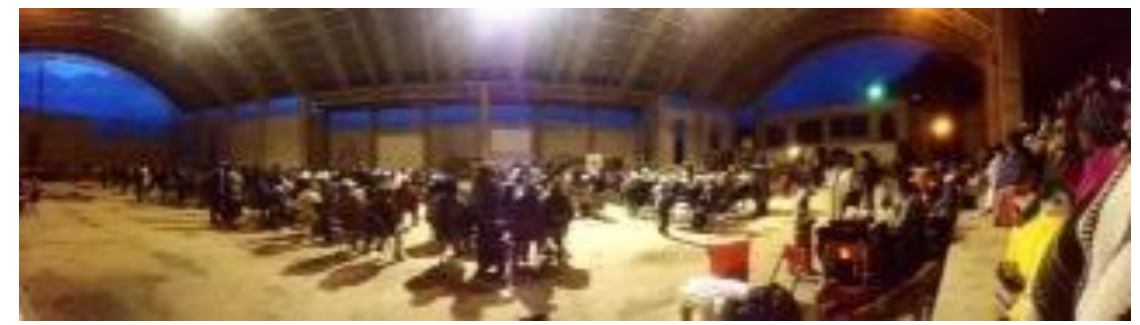

Imagen 2: Asamblea comunitaria de elección de autoridades en San Pedro y San Pablo Ayutla Octubre, 2014. Fuente: Ibarra, 2015, p. 57.

Así como existe la asamblea comunitaria como entidad política central, el sistema de cargos funciona para mujeres y para hombres en base a un escalafón específico y definido para las necesidades de la comunidad, articulando cargos cívicos, religiosos y agrarios. ${ }^{18}$ Esta estructura se mantiene año a año de acuerdo a un Reglamento Interno que ha construido el Comité de Escritura de este reglamento, en el cual se plasma las normas transmitidas de manera oral y que se han asentado a través de la costumbre. Respecto al sistema de cargos de la comunidad de San Pedro y San Pablo Ayutla es necesario señalar que, si bien muchas comunidades indígenas en Oaxaca y México se rigen por usos y costumbres, cada una presenta sus especificidades respecto a la forma de organizarse. En ese sentido, a través de la etnografía se pudo observar que, aunque Ayutla tenga comunidades vecinas ( $y$ sin siquiera tener fronteras muy claras con ellas), su sistema político posee particularidades específicas. Características específicas son, por ejemplo, las que han permitido que las mujeres participen en esta instancia en iguales condiciones que los

\footnotetext{
18 Estos últimos fueron introducidos por las disposiciones agrarias para las comunidades agrarias y ejidos. En el caso de las comunidades agrarias los cargos son presidente (o representante) y tesorero de Bienes Comunales.
} 
hombres, opinando y tomando decisiones. Así también es como se han insertado en el sistema de cargos, asumiendo servicios exponencialmente. Los cargos (o servicios) a la comunidad se desempeñan con la siguiente escala (de menor a mayor rango de responsabilidad y jerarquía):

a. Topiles ${ }^{19}$ y vocales de los diferentes comités.

b. Mayores y secretarios de los comités.

c. Comandantes, donadores de premios, capitanes, mayordomos y tesoreros de los comités.

d. Secretario municipal (tanto de la Presidencia como de la Sindicatura y Alcaldía), Secretario de Bienes Comunales y presidente de los comités de las escuelas, danzantes, Salud, DICONSA.

e. Tesorero, Presidente de la Banda Filarmónica, Tesorero de Bienes Comunales, del Templo y de agua potable.

f. Regidores, Presidente del Templo y de agua potable.

g. Síndico.

h. Presidente, Presidente de Bienes Comunales,

i. Alcalde.

De acuerdo con este orden es que se establecen las funciones y servicios de las y los comuneros. Además, para poder denominarse "comunero/a" y poder desempeñar cargos se deben cumplir ciertos requisitos específicos como:

1. Tener 18 años de edad.

2. Ser ciudadano o ciudadana de Ayutla mixe: originario de la comunidad, residente en el pueblo; originario del municipio de Ayutla, que tiene inmuebles en la comunidad y hace uso de los diferentes servicios; originario de la comunidad radicado en un lugar diferente fuera del municipio, incluyendo también a su familia (esposo/a, hijos/as); avecindado con familia originaria de Ayutla; avecindado con un tiempo considerable radicando en la comunidad.

3. Tomar en cuenta la escala de servicios de la comunidad.

19 Los topiles fungen como policías, hacen trabajos pesados, deben resguardar el orden público. Coloquialmente se dice que los topiles "hacen los mandados". Es el cargo más bajo y se debe comenzar siendo topil para poder acceder a cargos de mayor importancia. (Cruz Rueda, 2018) 
El sistema comunitario se basa en un ejercicio democrático que muchos plantean como "la verdadera democracia" por la posibilidad de tomar la palabra y ser escuchados (Ibarra, 2015). Esta configuración política está hecha para que cada una/o de los comuneros/as pueda participar, lo que se plantea como un deber, no solo como una posibilidad. Así planteó Carlos la manera en que funciona esta organización:

Se asignan cargos comunitarios por razones honoríficas. Aquí es por cuestión de honor. El sistema de cargos se basa en un servicio al pueblo, todas las familias deben participar. Además, se celebra el tequio, fiestas comunitarias, para nosotros estos ritos tienen una razón de ser. Si algo de eso falla, la vida en comunidad está en riesgo. Si se pierden las asambleas comunitarias, estamos en riesgo. Todo, si ya no se da el tequio, estamos en riesgo ya. Si no quiero desempeñar un cargo, o quiero cobrar por hacerlo, hay un riesgo. (Carlos) (Ibarra, 2015, p. 60)

Los servicios deben asumirse por un año, aunque el maestro Federico -comunero que ha ejercido diferentes cargos dentro del sistema- señaló que existen ciertas excepciones:

Los cargos de presidente en el cabildo, en su mayoría, han sido por un año. Por tradición los cargos en Ayutla son por un año. Pero hay algunos en 1969-7071, o del 75 al 77, del 78- 80, del 99 al 2001, han trabajado 2 o 3 años. Han sido excepciones. Cuando la asamblea se reúne, se elige a la autoridad para que dé su servicio por un año. $Y$ los que han trabajado 2 o 3 años ha sido porque se reúne nuevamente el pueblo y se han dado las reelecciones, pero no es tradición, es excepción. (Federico) (Ibarra, 2015, p. 61)

Han ocurrido transformaciones en la forma de organizar y ejercer el sistema de cargos, lo que nos habla de que es un sistema dinámico y mutable. Algunas de las transformaciones han repercutido en las formas de relacionarse entre géneros y entre generaciones (jóvenes y adultos), lo cual se ve, por ejemplo, en una creciente desmotivación de parte de hombres jóvenes para participar en el sistema de cargos comunal. Esto, a su vez, ha dado paso a que cada vez más mujeres desempeñen cargos $y$, por ende, se apropien de un espacio político en la comunidad. 


\section{Transformaciones que repercuten en el sistema político: observaciones etnográficas}

Si bien el sistema de cargos es importante en sí mismo, éste ya ha sido abordado profusamente para distintos pueblos y regiones de México (Cruz Rueda, 2018; Gómez Peralta, 2005; Padilla Pineda, 2000; Sandoval Forero et al., 2002). Por ello, en esta sección el abordaje se centra en las transformaciones que han afectado al sistema de cargos y el impacto que esto ha tenido en la vida política y comunitaria de Ayutla. A partir del trabajo etnográfico se identificó que una de las principales preocupaciones que algunos tienen (respecto al sistema de cargos) respecta a los pretextos y excusas que presentan los comuneros para no asumir el servicio (como haber ejercido alguno hace poco tiempo, o por estar estudiando o por problemas de salud en la familia, principalmente), lo que coloquialmente llaman "rebeldía". De acuerdo con lo manifestado por algunos comuneros, este asunto se ha vuelto recurrente en el municipio, por lo que los esfuerzos se han volcado a transformar esa situación y aumentar la participación de la comunidad.

El año 2013 dieciséis personas que fueron designadas para ejercer un cargo no lo hicieron, sin embargo, al no existir un reglamento formal en el cual basarse (más que la tradición oral) no se pudieron aplicar sanciones a los desertores. Con respecto a este tema, Ana (que asumió con el cargo de capitana de fiesta) y Ramón (su hermano), amigos y colaboradores de la investigación, dijeron que la falta de sanciones en el sistema de cargos provoca y permite la deserción y el incumplimiento de los deberes, por lo cual Ramón plantea que "se requiere algo de coerción para que el sistema funcione" (Ibarra, 2015, p. 88- 89).

Para los habitantes de San Pedro y San Pablo Ayutla el sistema de cargos, como proyecto, tiene el objetivo de ordenar y establecer reglas que permitan un buen funcionamiento de la vida en comunidad. El maestro Federico, quien fue el coordinador de la comisión del Reglamento Interno durante el año 2014, me explicó el propósito de este emprendimiento escritural:

Un reglamento debe ayudar a ver con claridad los compromisos, pero también los derechos. O sea, como ciudadano, si es por usos y costumbres, qué derechos valorar, qué elementos me ayudan para seguir sintiéndome ciudadano de Ayutla o sintiéndome de la región mixe. Y si se ocupara el reglamento sólo 
para sancionar, se convertiría en un material que, en lugar de ayudar a un desarrollo más agradable, más tranquilo, más feliz, sería un elemento que castigue, que sancione y en muchos lugares eso se da (Federico) (Ibarra, 2015, p. 89)

En ese sentido, el reglamento de Ayutla propuso un objetivo más allá de lo punitivo. Esto es una característica central en el derecho indígena, ya que la organización del sistema no se centra en la sanción, sino en la restauración del tejido social (Zolla \& Zolla Márquez, 2004). Es decir, si bien lo punitivo puede estar expresado en las normas, este no es el eje estructurador del derecho. En esta tónica podemos entender que la necesidad de normar el municipio a través de un reglamento escrito (no solo oral) que definiera las cuestiones elementales del sistema de cargos y de la normatividad interna no surge exclusivamente para castigar y obligar a los desertores, sino para promover la participación y, con ello, el sentido de comunalidad.

De acuerdo con algunos comuneros, el menester para escribir este reglamento surgió ante la falta de interés de participación en las asambleas: instancia de congregación masiva a la que llegaban muy pocos (entre 150 a 200 de un total de más de 600 comuneros/as). Además, se reflexionó que un estatuto escrito podría entregar mayor formalidad a las actividades que se desarrollan en el pueblo. De acuerdo con la maestra Esther: "El reglamento es para que se normen las cosas. Como una familia, cuando hay un hijo desobediente, hay que ponerle reglas" (Esther) (Ibarra, 2015: p. 89). Por ello, la necesidad de plasmar en papel un sistema que era fundamentalmente oral no nace con el objetivo de castigar y reprimir, sino de fortalecer la responsabilidad comunitaria, de distribuir y rotar los cargos y para que todas y todos tengan la posibilidad de participar y contribuir con la comunidad.

El primer punto que trabajó la comisión fue la asamblea y su importancia. Al finalizar este ítem se trató el tema del sistema de cargos, su funcionamiento y la posibilidad de llevar a cabo un censo que permitiera conocer cuánta población hay y con cuántas personas se cuenta para trabajar en el aparato de organización comunitaria. A partir de esa información (del factor numérico), de acuerdo con lo señalado, se puede tener una visión más amplia y lograr que los servicios se compartan y no se concentren en ciertas personas o familias. En definitiva, se están buscando mecanismos que promuevan que el sistema funcione y se evite la deserción aun cuando existe una 
alta desmotivación que se traduce en una evasión de los comuneros para no dar servicios.

En este contexto surge la pregunta respecto de ¿por qué los comuneros ya no quieren asumir los cargos? El trabajo etnográfico y la asistencia a algunas de las asambleas entregan algunas pistas. Por ejemplo, en la asamblea comunitaria de nombramiento de autoridades (el día 18 de octubre del año 2014) se observó que existen cargos percibidos como "castigo" más que como privilegio o distinción. Esto se relaciona a que no hay una búsqueda activa de poder, sino que los cargos son otorgados por experiencia $y$, sobre todo, por disponibilidad. En ese sentido, el poder está intrínsecamente ligado al servicio. De hecho, en lengua ayuujk no existe la palabra autoridad ligada al poder. Autoridad es la traducción de la palabra kutunk, que en español quiere decir algo similar a "servidor de la comunidad". Por lo que un cargo representa un servicio más que la ostentación de un puesto que implique ejercer autoridad vertical e impositiva. ${ }^{20}$ Así también lo señala María Luisa, antropóloga y esposa de un ex presidente municipal de esta comunidad, quien señala:

El sentido de poder allí en los mixes es un sentido de servicio al pueblo, inclusive también por parte de los hombres. Los hombres no compiten por el poder, sino que cumplen con un servicio que el pueblo les da. Y lo tienen que hacer porque, si no, quedan marginados de la sociedad. Pero si ves, hay toda una ceremonia de cuando se candidatean a las personas para ser presidentes, todas las personas dicen "no, yo no quiero ser presidente, yo trabajo afuera, soy maestro y no puedo pedir permiso para venir a cumplir el cargo, mi familia me apoya, pero yo no estoy buscando el cargo". Hay quienes dicen que "no estoy preparado, yo no soy quien, hay gente mucho más preparada que yo, con más experiencia". (María Luisa) (Ibarra, 2015, p. 90)

Durante las asambleas también se observó que algunos de los asistentes comienzan a abandonar poco a poco el lugar ante la oportunidad de una puerta abierta o la ausencia de un topil que vigile; posiblemente a lo extenso de las asambleas o por

20 En ese sentido, obtener y ejercer un cargo comunal implica un respeto y reconocimiento por parte de la comunidad. Esto se refleja al momento que la asamblea elige a las autoridades comunitarias, donde el voto se basa - principalmente- en la trayectoria moral y política de los candidatos. 
querer priorizar otras labores. A esto se suman problemas de coordinación de parte de las autoridades y de conflictos políticos no resueltos con las agencias, ${ }^{21}$ lo que se traduce en problemas en la convocatoria y asistencia de los comuneros provenientes de las agencias y ranchos cercanos.

Otra de las cuestiones que influyen en la baja participación y desmotivación es que en Ayutla el período de "descanso" entre un cargo y otro no está bien definido, aunque en teoría sería de aproximadamente 3 años. Pasado este periodo se vuelve a estar disponible para ocupar un cargo. Esto significa que un comunero, a lo largo de su vida, puede ocupar varios y consecutivos cargos, lo que se traduce en tiempo y energías invertidas en la labor. Esto se amplía si consideramos que hay un gran repertorio de cargos con relación a la cantidad de personas que está en posibilidad de cumplirlos. Así lo señala Yasna (una de las colaboradoras), quien dice que, "tomando en cuenta que es un pueblo con poca población (en comparación a los pueblos vecinos de Tamazulapam y Tlahuitoltepec), tiene por consecuencia que no hay suficiente gente como para ocupar los cargos, o al menos se hace mucho más difícil elegirlos" (Ibarra, 2015, p. 91). Todos estos factores traen como consecuencia una escasez de posibles servidores. Por esto es que Carlos postula que,

No es que la gente no quiera servir, sino que ellos dicen "pero si yo ya hice este servicio, otra vez me están nombrando para esto", porque también tradicionalmente se piensa que los cargos se asumen por jerarquía, empiezas con un servicio bajo y luego vas ascendiendo. Pero ha resultado que en la misma asamblea se ha nombrado a algunas personas con algunos cargos sin tomar en cuenta la escala. Y entonces se piensa "pero por qué está en ese cargo tan alto", pero eso lo hace la asamblea. Entonces como que nos falta un poco más de organización en ese aspecto, porque luego también dicen "yo ya di este servicio y hay muchos otros que nadie se acuerda de ellos y no han dado servicio". Entonces también queremos hacer un censo que nos dé un panorama más amplio, que nos diga pues este señor ya hizo estos servicios, pero mira

21 Las agencias municipales son localidades que, dependiendo de su tamaño, son reconocidas administrativa y políticamente por la cabecera municipal (la localidad más importante y numerosa del municipio). En el caso del municipio de San Pedro y San Pablo Ayutla, éste está compuesto por la cabecera municipal (San Pedro y San Pablo Ayutla) y cinco agencias municipales que son Lachicocana, Duraznal, El Portillo Matagallinas, Cerro del Amole y Cerro Pelón, además de otras localidades más pequeñas, también llamadas rancherías. 
este otro no ha hecho más que uno o dos. Entonces para que sea algo más equilibrado, con información podremos saber quiénes estamos aquí, quiénes están afuera, quiénes estudian, quiénes tienen bienes aquí, algo que nos posibilite tener una visión más amplia de tal manera que se compartan los servicios. Y con más información se pueden prever varias cosas con esto del censo. (Carlos) (Ibarra, 2015, p. 91)

Sin embargo, la desmotivación no solo se relaciona a factores intracomunitarios, como los ya mencionados, también existen influencias externas que han calado en el sentido de comunalidad forjado a través de la cooperación, la ayuda mutua, la convivencia y el trabajo comunal de las familias extensas que conforman la comunidad (Nahmad Sitton, 1994, p. 485). Esta influencia externa se traduce, principalmente, en que lo individual desplaza a lo comunal: actuar en beneficio propio y no bajo una lógica comunal. La comunalidad se ha visto impugnada por la racionalidad occidental en, al menos, dos frentes: uno social y otro individual. En el primer aspecto, el pensamiento occidental ve en la comunidad indígena (y la comunalidad) un resabio del pasado sustentado en un uso irracional de los recursos en el que, por ejemplo, los bienes son distribuidos según criterios extraeconómicos. Para estos críticos la administración comunal tiene el peligroso defecto de ponderar como superior ideales de justicia en desmedro de la eficiencia, poniendo en riesgo la supervivencia colectiva. Sin embargo, esta visión desconoce, por un lado, la experiencia de estas comunidades para dar alivio a condiciones de emergencia y escasez a lo largo de varios siglos de historia, es decir, no están improvisando, y, por el otro, olvida que los bienes son comunales no solo porque todos los consuman sino también porque todos concurren para protegerlos.

Un segundo cuestionamiento a la comunalidad viene del hecho de que sean cada vez menos los jóvenes que se integran al trabajo colectivo, por lo que en no pocas oportunidades se ha indicado que ese tipo de administración maltrata al no remunerar con un salario al individuo. Esta crítica se apoya en un hecho cierto, pero su conclusión es amañada: si bien los jóvenes participan cada vez menos de la vida comunal, lo hacen porque se ven obligados a trabajar por un salario para comprar las mercancías que necesitan. Este avasallamiento del mundo de las mercancías no es una opción para ellos, sino una necesidad, a pesar de la importancia que todavía le atribuyen al reconocimiento social, el prestigio y otros valores sociales. 
Entonces, debemos considerar que la comunidad, y las relaciones que se tejen en ella, no pueden analizarse como autocontenidas, sino que se deben considerar en contextos más amplios que influencian las relaciones sociales dentro de la comunidad. Así, el sistema neoliberal desigual e individualista que rige hoy, ha calado hondo oprimiendo de tal manera que desconecta al ser humano del ser político, reproduciendo comportamientos egoístas, indolentes y poco empáticos con el otro y, en este caso, con la comunidad. Esta ideología enaltece al éxito económico resaltando como valor fundamental, relegando, a su vez, la solidaridad, la ayuda mutua o el trabajo mancomunado a actividades de filantropía. Este cambio de racionalidad se está desarrollando y repercutiendo en las relaciones de la comunidad. Algunos comuneros plantean que se está perdiendo el espíritu de servicio, lo que implica, por ejemplo, que los cargos sean aprovechados con fines utilitaristas como, por ejemplo, posición estratégica (aprovechando el prestigio y respeto dentro de la comunidad), catapulta política o, incluso, buscando recursos económicos. Esto desequilibra las relaciones sociales y el sentido de comunidad, constituyéndose como las principales amenazas que minan el principio de comunalidad:

Por cierto sí, van disminuyendo, perdiendo fuerza algunas tradiciones. Como la del tequio va perdiendo fuerza; o la del servicio voluntario que en otros pueblos todavía existe, en los cargos. Aquí todos tienen que pasar por un cargo para poder tener posesión de su terreno, pero aquí se ha ido perdiendo por la misma situación de las relaciones sociales y comerciales, algunos pagan el tequio, o el servicio también lo pagan. El mismo flujo y reflujo de personas hace que se vaya perdiendo aquí más que en otros lados. (Obispo de Ayutla) (Ibarra, 2015, p. 92)

Otra de las instituciones que se ha visto afectada por los cambios e influencias (internas y externas) ha sido el tequio o trabajo comunal, el cual se basa en el trabajo mancomunado (sin remuneración) para beneficio de la comunidad (Zolla \& Zolla Márquez, 2004). El tequio es clave en comunidades donde los recursos públicos escasean, o son insuficientes para, por ejemplo, mejorar una calle, extender un servicio público (agua, luz) o delimitar linderos. Esta forma de asumir colectivamente un trabajo en beneficio de la comunidad se ve amenazada por la poca transparencia al momento de adjudicar los fondos por los municipios. Así, los municipios prefieren pagar para la ejecución de un trabajo específico. Al respecto, los comuneros 
reflexionan que "a todos les parece más fácil que otro lo haga en vez de que a mí me llamen, total ese dinero llegó por recursos federales canalizados a una obra que se supone que es en beneficio de la comunidad" (Carlos) (Ibarra 2015, p. 93). Esto ha implicado que, por un lado, los municipios sean poco transparentes al momento de administrar el dinero y ejecutar las obras de infraestructura ${ }^{22}$ o que localidades más pequeñas queden prácticamente abandonadas; por otro lado, los comuneros buscan desentenderse del trabajo comunitario a sabiendas de que existe un recurso monetario exclusivo para las obras de infraestructura (ramo $28^{23}$ ). A su vez, esto genera conflictos internos dentro de las comunidades, como fue lo que ocurrió el año 2014 con la agencia de Lachicocana. Así me lo explicó la maestra Esther, quien estaba de presidenta municipal en ese momento:

El problema es que el recurso con las agencias se distribuye, por ejemplo, con el ramo 28 vamos a suponer que nosotros recibimos del ramo $28 \ldots$ ¿qué será? 9 millones, por ejemplo. El 50\% se queda para la cabecera y el otro $50 \%$ se divide en las agencias de manera proporcional. Entonces hay una que quizás diga "a mí me toca más porque mi agencia es mucho más grande" y lo quiere por número de habitantes. Si se hace por número de habitantes, se conflictúa con los pequeños, porque lógico, les va a tocar menos. Entonces lo que se determina es que tiene que ser de acuerdo con sus necesidades. Si hay una agencia, por muy pequeñita que sea, pero le hace falta más aulas, por decir algo, o le falta electrificación o drenaje, por decir algo, bueno entonces a esa agencia se le tendría que dar más porque es la que tiene más necesidades. Y la otra grande que ya tiene cubiertas sus necesidades le tendría que tocar menos, independientemente que tenga mayor número de habitantes. Debería de ser. Pero acá por usos y costumbres no se hace así. Tiene que hacerse de manera proporcional, de acuerdo con el tamaño te toca esta parte, por decir algo. Y así lo hemos hecho. Pero se alega que por qué unos más si son más chicos que nosotros, es como los hermanos, que el más grande quiere más y

\footnotetext{
22 Durante el trabajo de campo se asistió a 3 asambleas convocadas para dar a conocer el informe financiero del cabildo del año 2013, sin embargo, ninguna se llevó a cabo. Finalmente, el informe fue pospuesto para el año siguiente, lo que generó un desajuste ya que se juntaría con el informe del año 2014 (Ibarra, 2015, p. 93)

${ }^{23}$ El ramo 28 es un apartado del presupuesto nacional; son los recursos asignados a los estados y municipios para fortalecer sus gobiernos locales.
} 
al chiquito dale menos, si es chiquito. Entonces el problema es que una agencia quiere más y ya no subía a las reuniones: Lachicocana. (Esther) (Ibarra, 2015, p. 93)

Otra de las cuestiones que se han transformado es lo que respecta a la remuneración del cargo. Esta remuneración es una suerte de "secreto a voces", ya que muchos lo niegan, pero hay quienes han señalado que se recibe un sueldo, que en muchos de los casos es simbólico. Esta remuneración se maneja con discreción porque supone un cuestionamiento moral a la persona, dado que un servicio no debería ser remunerado:

Los que sí sé que reciben remuneración son los topiles. No es mucho, pero sí les pagan. Sí reciben una quincena, yo sé porque me llevo con muchos de ellos. iEntonces eso ya no es servicio! Les dan de comer, les pagan... Un mínimo, creo que por quincena son como 700 pesos. (Roberta) (Ibarra, 2015, p. 94)

Aunque en la sierra mixe es casi imposible hacer generalizaciones entre diferentes comunidades, es importante destacar lo que el ex alcalde de la comunidad de Totontepec plantea respecto de los dilemas que se plantean respecto del servicio a la comunidad:

En las comunidades originarias, erróneamente llamadas indígenas, la idea de perdedores y ganadores en el juego del poder no existe. En nuestro caso el aparente perdedor en los votos es un ganador porque su familia asegura un año más de sostén económico y moral, en cambio, el ganador en votos podría decirse que es un perdedor para su situación y para su familia, pero la comunidad gana al poder dar continuidad a las instituciones del gobierno tradicional, los intereses individuales son supeditados a los colectivos y por tanto no se puede hablar estrictamente de un perdedor, al ganar la comunidad, la persona electa también gana, por ser miembro de la comunidad. (Alcántara Núñez, 2004, p. 27)

La comunalidad como ejercicio de autonomía tiene que ver con la forma en que las personas habitantes de un territorio construyen un entramado sociopolítico de colaboración y apoyo mutuo. Las transformaciones culturales han afectado al funcionamiento del sistema de cargos y ha habido un impacto en la vida política y comunitaria de Ayutla. Sin embargo, el sistema normativo interno se mantiene como 
un elemento central que configura una experiencia particular de autonomía territorial de esta comunidad mixe.

\section{Reflexiones finales}

Cada una de las transformaciones descritas nos muestran que el sistema normativo de comunidades como Ayutla no son inmutables, sino que están en constantes transformaciones que suponen conflictos internos, pugnas o disidencias. Al mismo tiempo, muestran la resistencia diaria de las comunidades por gobernar sus territorios en términos propios, es decir, de acuerdo con lo que para ellos es importante, como el territorio, la participación o la comunalidad.

En ese sentido, es importante tener claro que este tipo de experiencias distan mucho de ser perfectas, sin embargo, nos muestran un horizonte de expectativas en el que las comunidades luchan cotidianamente por desarrollar una forma particular de ser y estar en el territorio, lo que nos aproxima a una experiencia de autonomía relacional indígena, la cual debe ser entendida:

Como la capacidad de los pueblos indígenas para ejercer autodeterminación y gobernabilidad en sus territorios a partir de las relaciones, negociaciones, confrontación y participación que tienen que establecer con el Estado y diversos actores locales, nacionales y transnacionales en la búsqueda de reconocimiento e implementación de su autonomía política y territorial; aun cuando retomen políticas o procesos estatales o transnacionales en la búsqueda de su consolidación. (Ulloa, 2010, p. 79)

Esas autonomías debemos pensarlas desde lo local, de manera situada y en contextos específicos, pero sin olvidar los marcos más amplios que afectan las configuraciones de las autonomías indígenas, como en el caso que abordamos sobre Ayutla y las transformaciones en sus formas de gobierno comunal.

Por lo tanto, la experiencia etnográfica con el pueblo mixe nos permitió aproximarnos a la autonomía relacional indígena retomando -desde las prácticas comunitarias- las configuraciones de poder, el sistema normativo interno, el sentido de comunalidad (y las transformaciones en estos) en su relación con la autonomía. 
Uno de los hallazgos importantes fue comprender que las configuraciones de poder están ligadas intrínsecamente al servicio, como el mismo concepto de kutunk expresa, entonces la intromisión de la racionalidad instrumental interfiere en la forma en que el servicio/cargo se desarrolla: su sentido se trastoca ya que la comunalidad define la inmanencia de la comunidad, y uno de los elementos propios es el servicio gratuito como ejercicio de autoridad (Díaz Gómez, 2004). Por lo tanto, al cuestionar la organización y funcionamiento del sistema de cargos se debate, en sí mismo, el concepto de comunalidad. Es decir, se pone en entredicho valores que promueven el sentido de comunidad como la ayuda mutua, el trabajo mancomunado, la participación directa y la injerencia sobre la vida comunitaria. Este cuestionamiento no implica que el sistema de cargos esté ante una fractura inminente, sino que nos muestra que el derecho indígena está en constante transformación ante procesos contenciosos que implican la organización de la comunidad y la búsqueda de estrategias para proteger el territorio.

En Ayutla existe una preocupación latente por la participación y el mantenimiento de formas tradicionales de organizar y gobernar el territorio. Desde la misma comunidad existen claridades respecto a las causas y consecuencias de estas transformaciones sobre la vida comunal. Aún con los conflictos internos que puedan existir respecto del funcionamiento del sistema normativo interno, se reconoce la relevancia de un sistema independiente para mantener y potenciar la vida política comunitaria que permite la autonomía local. Son los mismos comuneros y comuneras los que deciden las temáticas que incumben a los habitantes del territorio: son ellos y ellas quienes resuelven las problemáticas a mano alzada y tomando la palabra.

\section{Bibliografía}

Alcántara Núñez, H. (2004). Usos y costumbres: Vivencias y convivencias de un alcalde mixe (1. ed). México: CONACULTA.

Altman, I., \& Low, S. M. (Eds.). (1992). Place Attachment. New York: Plenum Press. Aparicio, M. (2009). La libre determinación y la autonomía de los pueblos indígenas: El caso de México. Boletín mexicano de derecho comparado, 42, 13-38. Extraído de http://www.scielo.org.mx/pdf/bmdc/v42n124/v42n124a1.pdf 
Aquino Centeno, S. (2013). Interrogando la costumbre y la legislación indígena: Contribuciones y horizontes de la antropología jurídica en Oaxaca. Nueva antropología, 26(78), 87-117. Extraído de http://www.scielo.org.mx/pdf/na/v26n78/v26n78a5.pdf

Barabas, A. M. (2014). La territorialidad indígena en el México contemporáneo. Chungará Revista de Antropología Chilena, 46(3), 437-452. http://dx.doi.org/10.4067/S0717-73562014000300008.

Bengoa, J. (2007), La emergencia indígena en América latina, Santiago de Chile y México: Fondo de Cultura Económica

Bonfil Sánchez, P., Barrera Bassols, D., \& Aguirre Pérez, I. (2008). Los espacios conquistados: Participación política y liderazgo de las mujeres indígenas de México. México: Programa de las Naciones Unidas para el Desarrollo.

Canedo Vásquez, G. (2008). Una conquista indígena. Reconocimiento de municipios por usos y costumbres en Oaxaca (México). En A. D. Cimadamore (Ed.), La economía política de la pobreza (1. ed, pp. 401-426). Buenos Aires: CLACSO.

Cruz Rueda, E. (2018). Derecho indígena: Dinámicas jurídicas, construcción del derecho y procesos de disputa [recurso electrónico] (Primera edición). México, DF.: Instituto Nacional de Antropología e Historia.

Cruz Rueda, E. (2019). El derecho indígena como impulsor del pluralismo jurídico en el derecho mexicano. Diálogo Andino, 59, 131-142. https://dx.doi.org/10.4067/S0719-26812019000200131

Díaz Gómez, F. (2004). Comunidad y comunalidad. En Culturas Populares e Indígenas \& Consejo Nacional para la Cultura y las Artes, Antología sobre culturas populares e indígena: Lecturas del seminario Diálogos en la Acción.: Vol. II Segunda Etapa (pp. 365-373). México: CONACULTA, Dirección General de Culturas Populares e Indígenas.

Durand Ponte, V. M. (2007). Prólogo. En J. Hernández Díaz (Ed.), Ciudadanías diferenciadas en un estado multicultural: Los usos y costumbres en Oaxaca (1. ed, pp. 11-34). México: Siglo XXI Editores; Universidad Autónoma Benito Juárez de Oaxaca. 
Elden, S. (2010). Land, terrain, territory. Progress in Human Geography, 34(6), 799817. https://doi.org/10.1177/0309132510362603

Evans, J., \& Jones, P. (2011). The Walking Interview: Methodology, Mobility and Place. Applied Geography 31: 849-858.

Gaussens, P. (2019). Por usos y costumbres: Los sistemas comunitarios de gobierno en la Costa Chica de Guerrero. Estudios sociológicos, 37, 659-687. https://doi.org/10.24201/es.2019v37n111.1723

Gómez Peralta, H. (2005). Los usos y costumbres en las comunidades indígenas de los Altos de Chiapas como una estructura conservadora. Estudios políticos, 5, 121-144. https://doi.org/10.22201/fcpys.24484903e.2005.5.37657.

Hernández-Díaz, J. (Ed.). (2007). Ciudadanías diferenciadas en un estado multicultural: Los usos y costumbres en Oaxaca (1. ed). México: Siglo XXI Editores; Universidad Autónoma Benito Juárez de Oaxaca.

Hoechli, T. (2013). Intervención y organización social: Los frutos dulces y amargos en la construcción de la red de mujeres mixes [Maestría en Desarrollo Rural]. Universidad Autónoma Metropolitana. Extraído de https://biblioteca.xoc.uam.mx/tesis.htm?fecha $=00000000 \& a r c h i v o=c d t 1941$ 29uvbi.pdf\&bibliografico $=191039$

Ibarra, M. I. (2015). Participación comunitaria y política de mujeres en una comunidad mixe: Etnografía en San Pedro y San Pablo Ayutla, Oaxaca [Maestría en Antropología Social, Universidad Iberoamericana]. http://ri.ibero.mx/bitstream/handle/ibero/440/016013s.pdf?sequence=1\&is Allowed $=y$

INEGI. (2020). Estadísticas a propósito del día internacional de los pueblos indígenas (9 de agosto) [Comunicado de prensa Núm. 392/2020]. Instituto Nacional de Estadística y Geografía. https://www.inegi.org.mx/contenidos/saladeprensa/aproposito/2020/indigen as2020.pdf

Instituto Estatal Electoral y de Participación Ciudadana de Oaxaca. (2018, octubre). Catálogo de municipios sujetos al régimen de sistemas normativos indígenas 2018

[Comunicado]. 
http://www.ieepco.org.mx/archivos/documentos/2018/cat\%C3\%A1logo\%20 sistemas/Presentacion.pdf

López Bárcenas, F. (2002). El derecho indígena y la teoría del derecho. En A. Peña Jumpa, V. J. Cabedo Mallol, \& F. López Bárcenas (Eds.), Constituciones, derecho y justicia en los pueblos indígenas de América Latina. Análisis constitucional; justicia y derecho oaxaqueño (México); justicia y derecho aymara (Perú) (1. ed, pp. 180-204). Perú: Pontificia Univ. Católica del Perú.

López Santiago, N., \& Barajas Gómez, V. (2013). Identidad y desarrollo: el caso de la subregión alta mixe de Oaxaca. Península, 7(2), 9-37.

Marimán, J. A. (2012). Autodeterminación: Ideas políticas mapuche en el albor del siglo XXI (Primera edición). Santiago, Chile: LOM Ediciones.

Nahmad Sitton, S. (Ed.). (1994). Fuentes etnológicas para el estudio de los pueblos ayuuk (mixes) del Estado de Oaxaca (1. ed). Oaxaca, México: CIESASOaxaca; Instituto Oaxaqueño de las Culturas.

Nogué, J. (2015). Sentido del lugar, paisaje y conflicto. Geopolítica(s). Revista De Estudios Sobre Espacio Y Poder, 5(2), 155-163. https://doi.org/10.5209/rev_GEOP.2014.v5.n2.48842

Oslender, U. (1999). Espacializando resistencia: Perspectivas de «espacio» y «lugar» en las investigaciones de movimientos sociales. Cuadernos de Geografía: Revista Colombiana de Geografía, 8(1), 1-35. Extraído de https://revistas.unal.edu.co/index.php/rcg/article/view/71603

Padilla Pineda, M. (2000). Ciclo festivo y orden ceremonial: El sistema de cargos religiosos en San Pedro Ocumicho. Zamora, México: El Colegio de Michoacán.

Sámano, M., Durand, C. H., \& Gómez, G. (2001). Los acuerdos de San Andrés Larráinzar en el contexto de la declaración de los derechos de los pueblos americanos. En J. E. Ordóñez Cifuentes, Análisis interdisciplinario de la Declaración Americana de los Derechos de los Pueblos Indígenas: X Jornadas Lascasianas (pp. 103-120). México, DF.: Universidad Nacional Autónoma de México: Instituto de Investigaciones Jurídicas.

Sánchez, C. (2010). Estados pluninacionales y pluriétnicos. En M. González Pérez, A. Burguete Cal y Mayor, \& P. Ortiz-T. (Eds.), La autonomía a debate: 
Autogobierno indígena y estado plurinacional en América Latina (1a. ed, pp. 259-288). FLACSO Ecuador; GTZ; Ministerio Federal de Cooperación Económica y Desarrollo: IWGIA; CIESAS; Universidad Intercultural de Chiapas

Sandoval Forero, E., Topete Lara, H., \& Korsbaek, L. (Eds.). (2002). Cargos, fiestas, comunidades (1a ed). Toluca, México: Universidad Autónoma del Estado de México.

Sierra Camacho, M. T. (1993). Usos y desusos del derecho consuetudinario indígena. Nueva Antropología, 13(44), 17-23. Extraído de https://www.redalyc.org/pdf/159/15904403.pdf

Sierra Camacho, M. T. (1997). Esencialismo y autonomía: Paradojas de las reivindicaciones indígenas. Alteridades, 7(14), 131-143. Extraído dehttps://www.inegi.org.mx/contenidos/saladeprensa/aproposito/2020/indig enas2020.pdf

Sierra Camacho, M. T., \& López, E. L. (2013). Dictamen pericial antropológico y los sistemas normativos en el municipio de San Luis Acatlán, Guerrero. México, DF.: CIESAS. Extraído de https://mariateresasierra.files.wordpress.com/2018/05/dictamen-pdf.pdf

Ulloa, A. (2010). Reconfiguraciones conceptuales, políticas y territoriales en las demandas de autonomía de los pueblos indígenas en Colombia. Tabula Rasa, 13, 73-92. https://doi.org/10.25058/20112742.405

Ulloa, A. (2015). Environment and development: Reflections from Latin America. En T. A. Perreault, G. Bridge, \& J. McCarthy (Eds.), The Routledge handbook of political ecology (pp. 320-331). London; New York: Routledge, Taylor \& Francis Group.

Zolla, C., \& Zolla Márquez, E. (2004). Los pueblos indígenas de México: 100 preguntas. México, DF.: Universidad Nacional Autónoma de México. 